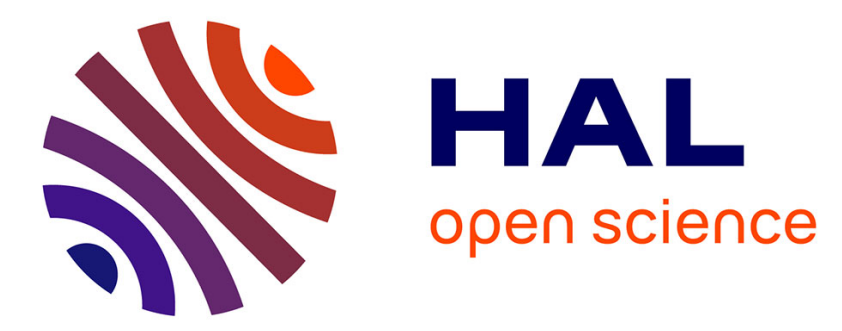

\title{
Evolution of Fe3+ from Framework to Extra-Framework Species in Fe-Silicate as a Function of the Template Burning Temperature
}

S. Bordiga, D. Scarano, C. Lamberti, A. Zecchina, F. Geobaldo, G. Vlaic, R. Buzzoni, G. Tozzola, G. Petrini

\section{To cite this version:}

S. Bordiga, D. Scarano, C. Lamberti, A. Zecchina, F. Geobaldo, et al.. Evolution of Fe3+ from Framework to Extra-Framework Species in Fe-Silicate as a Function of the Template Burning Temperature. Journal de Physique IV Proceedings, 1997, 7 (C2), pp.C2-907-C2-908. 10.1051/jp4:1997275 . jpa00255358

\section{HAL Id: jpa-00255358 https://hal.science/jpa-00255358}

Submitted on 1 Jan 1997

HAL is a multi-disciplinary open access archive for the deposit and dissemination of scientific research documents, whether they are published or not. The documents may come from teaching and research institutions in France or abroad, or from public or private research centers.
L'archive ouverte pluridisciplinaire HAL, est destinée au dépôt et à la diffusion de documents scientifiques de niveau recherche, publiés ou non, émanant des établissements d'enseignement et de recherche français ou étrangers, des laboratoires publics ou privés. 


\title{
Evolution of $\mathrm{Fe}^{3+}$ from Framework to Extra-Framework Species in Fe-Silicate as a Function of the Template Burning Temperature
}

\author{
S. Bordiga, D. Scarano, C. Lamberti, A. Zecchina, F. Geobaldo*, G. Vlaic**, R. Buzzoni***, \\ G. Tozzola*** and G. Petrini***
}

\author{
Dipartimento di Chimica I.F.M., Via P. Giuria 7, 10125 Torino, Italy \\ * Dipartimento di Scienza dei Materiali e Ingegneria Chimica Politecnico Torino, Italy \\ ** Dipartimento di Scienze Chimice e Sincrotrone Trieste SCPA, Trieste, Italy \\ *** ENICHEM SpA, Centro di Ricerche di Novara, Via G. Fauser 4, Novara, Italy
}

\begin{abstract}
We report a XAFS study of the $\mathrm{Fe}^{3+}$ local environment in Fe-silicalite as a function of the template burning temperature. We investigate the structural changes of the zeolitic structure, upon thermal treatments and interaction with $\mathrm{NH}_{3}$. Our XAFS results show that, before template burning, $\mathrm{Fe}^{3+}$ are in tetrahedral symmetry with 4 oxygens at $1.85 \AA$, while after template removal and in vacuum conditions, they exhibit a distorted tetrahedral symmetry with 3 oxygens at 1.87 $\AA$, and one at $2.10 \AA$; dosage of $\mathrm{NH}_{3}$ partially restore the tetrahedral symmetry of the site. These results are strongly supported by parallel IR, Raman, UV-Vis, TPR and EPR investigations and by recent theoretical simulations.
\end{abstract}

\section{RESULTS AND DISCUSSION}

Isomorphous substitution of a small fraction (1-2 wt\%) of $\mathrm{Si}^{4+}$ with $\mathrm{Fe}^{3+}$ in silicalite framework, leads to the $\mathrm{Fe}$-silicalite $(\mathrm{Fe}-\mathrm{S})$ structure $[1,2]$. The presence in the zeolitic framework of $\mathrm{Fe}^{3+}$ species causes the appearance of an extra negative charge in the framework which must be compensated by protons in the form of bridged hydroxyls having an acidic strength very close to that observed in H-ZSM-5. It has been reported that the stability the eteroatom in the framework for the two structures is very different [2]: in fact template burning in $\mathrm{Fe}$-S with the associated water production is sufficient to cause the breaking of some bonds connecting iron with the oxygens of the framework and to induce migration of the iron into extraframework positions [2-4]. Because of this, a decrease of the framework iron species and the simultaneous appearance of oxidic micro aggregates are observed after calcination in an percentage increasing with the burning temperature [4,5]. Since the catalytic properties of Fe-S are strictly related to the characteristics of framework and/or extra-framework species, the determination of the location and of the aggregation state of iron species is of paramount importance in the characterization of acidic, catalytic and shape-selective properties of $\mathrm{Fe}-\mathrm{S}$ (see e.g. the introduction of ref. [4] and quoted refs.). Consequently it is a matter of primary importance to follow the framework zeolite evolution upon thermal treatments, starting from a virgin sample still containing the template up to the final sample calcined at high temperature. In this contribution we have investigated the structure of both framework or extraframework sites by means of XANES and EXAFS spectroscopies on a pure $\mathrm{Fe}$-silicalite after different treatment stages i.e.: an Fe-S as synthesized (indicated as $\mathrm{FeS}$ ), and samples calcined in air at 773 and $973 \mathrm{~K}$ (indicated as FeSC1 and FeSC2). For the last two samples the modification of the iron environment upon $\mathrm{NH}_{3}$ dosage will also be discussed.

XAFS spectra have been collected in the transmission mode, at the EXAFS3 beam line of LURE in Orsay (F), equipped with a double crystal $\mathrm{Si}(311)$ monochromator (calibrated with a Fe foil) and air filled ionization chambers. Sampling step was 0.3 and $2.0 \mathrm{eV}$ for XANES and EXAFS spectra respectively. The former were background subtracted with a linear function in the energy range $7090-7110 \mathrm{eV}$; the spectra were then normalized to unity in the continuum at $7190 \mathrm{eV}$. The latter were analyzed following standard procedures [6] using Michalovicz programs [7]: polynomial function (third degree) has been used to extract $\chi(k) ; k^{3}$ weighted FT were computed in the range 4-13 $\AA^{-1}$ using a Kaiser window with $\tau=3$. Data analysis were obtained in the frame of single scattering curved wave approximation extracting the experimental phase shift and amplitude functions from $\left(\mathrm{FePO}_{4}\right)$ model compound.

$\mathrm{Fe}^{3+} \mathrm{K}$-edge absorption spectra is characterized by a small pre-edge peak due to $1 s \rightarrow 3 d$ transitions. In ideal systems having a perfect octahedral symmetry these transitions are Laporte forbidden, nevertheless in real systems, where distortions from the perfect octahedral symmetry are very common, the loss of the inversion center and a partial mixing of $p$ and $d$ levels is often observed with subsequent gain of the pre-edge transitions intensity. On the contrary, systems with tetrahedral symmetry, having no inversion center and strong $d-p$ mixing, are characterized by an intense peak in the pre edge region due to the allowed transition from the ground state $A_{1}$ to the final state $T_{2}[3,4,8,9]$. We have thus used the normalized intensity of the XANES $1 s \rightarrow 3 d$ pre-edge peak to qualitatively discuss the symmetry of iron species present in the investigated samples. Reported in Fig.1 are the pre edge peak regions of FeS, FeSC1 and FeSC2 spectra (spectra obtained in the presence of $\mathrm{NH}_{3}$ are reported as dashed lines, while those obtained in vacuo are shown as full lines). For sake of comparison Fig. 1 also reports the pre-edge region of two model compounds with tetrahedral $\left(\mathrm{FePO}_{4}\right)$ and octahedral $\left(\mathrm{Fe}_{2} \mathrm{O}_{3}\right)$ coordination. The pre-edge spectra of $\mathrm{Fe}-\mathrm{S}$ samples are characterized by a well-defined single peak whose intensity, energy and full width at half maximum (FWHM) is sensitive to calcination treatments and to adsorbates interaction $[3,4,10]$. The qualitative agreement of pre-edge data obtained for $\mathrm{FeS}$ and $\mathrm{FeSCl}$ samples with those of $\mathrm{FePO}_{4}$ (which is considered a good model compound for tetrahedrally coordinated $\mathrm{Fe}^{3+}$ species) indicates that a high concentration of nearly perfect tetrahedrally coordinated $\mathrm{Fe}^{3+}$ species is present in these systems. From the previous considerations, it is evident that the pre edge peak intensity is directly related to the percentage of $\mathrm{Fe}^{3+}$ in tetrahedral coordination (which substitute for $\mathrm{Si}^{4+}$ in the 
framework). From Fig. I it is evident that on passing from sample FeS to FeSC1 and especially to FeSC2, the pre-edge peak intensity decreases, and the FWHM increases. The progressive intensity decrease induced by calcination (small in FeSCl and large in $\mathrm{FeSC} 2$ ) accompanied by a clear broadening, indicates that the calcination procedure causes a progressive migration of framework $\mathrm{Fe}^{3+}$ species towards extra-framework positions with formation of oxidic microaggregates. The persistence of a distinct (although broadened) single pre edge peak, without the splitting pattern characteristic of the model compounds with octahedral symmetry [9] (see $\mathrm{Fe}_{2} \mathrm{O}_{3}$ ) suggests that the fraction of large oxidic aggregates containing a high percentage of octahedral $\mathrm{Fe}^{3+}$ is still very low. The low concentration of bulky species is not surprising: in fact, if $\mathrm{Fe}_{2} \mathrm{O}_{3}$ clusters are formed inside the zeolite channels and at their intersection (diameter; $5.5 \AA$ ), only microaggregates. with less than 3-5 $\mathrm{Fe}_{2} \mathrm{O}_{3}$ units can be formed, which contain a negligible proportion of $\mathrm{Fe}^{3+}$ with octahedral configuration and a large fraction of low coordinated surface ions. $\mathrm{NH}_{3}$ dosage on $\mathrm{FeSC1}$ and $\mathrm{FeSC} 2$ induces a parallel intensity increase of the pre edge peak: this suggest that the amount of $\mathrm{Fe}^{3+}$ ions interacting with adsorbates is analogous in FeSCl and FeSC2. EXAFS analysis has been performed on $\mathrm{FeS}$ and FeCS1 (in vacuum and in presence of $\mathrm{NH}_{3}$ ) samples and corresponding fits are reported in Fig. 2. Main results can be summarized as follows: i) FeS sample is characterized by the presence of $\mathrm{Fe}^{3+}$ 4-fold coordinated with a Fe-O distance of $1.85 \AA$; ii) for FeSC1 in vacuo a two-oxygen shell fit is needed ( 3 oxygens at $1.86 \AA$ and 1 at $2.07 \AA$ ), in agreement with simulations carried out using the standard lattice energy minimization [12]; iii) EXAFS spectrum of FeSCl sample in the presence of $\mathrm{NH}_{3}$ is fitted with a single oxygen-shell (4 atoms at $1.86 \AA$ ) corresponding to an $\mathrm{Fe}^{3+}$ surrounding more homogeneous than in the FeSCl sample in vacuo: in particular both coordination number and distances are compatible with tetrahedral $\mathrm{Fe}^{3+}$ species in $\left[\mathrm{FeO}_{4}\right]^{-}$units hydrogen bonded to protonated ammonia. In conclusion: i) In FeSCl most of the $\mathrm{Fe}^{3+}$ species are in the framework with a distorted tetrahedral symmetry (in vacuo) ii) FeSCl contains also extra-

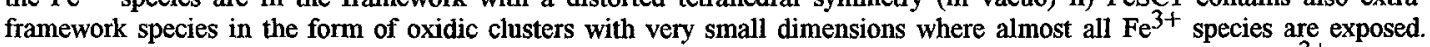
These ions seem to reach a distorted tetrahedral symmetry in presence of ligands. iii) In FeSC2 nearly all the Fe ${ }^{3+}$ ions are in extra-framework position and form aggregates containing a high concentration of surface ions which can interact with adsorbates assuming distorted tetrahedral symmetry. The evidence that in FeSC2 sample highly dispersed low-coordinated extra-framework $\mathrm{Fe}^{3+}$ species are present, is in perfect agreement with the high catalytic activity of this zeolite in oxidation reactions. These data are strongly supported by parallel investigation using UV-Vis $[3,4], \mathbb{R}$ and Raman $[4,11]$, TPR, and EPR data [4], and by IR spectroscopy of $\mathrm{CO}$ and $\mathrm{N}_{2}$ dosed at $77 \mathrm{~K}$ [5]. The helpful assistance of F. Villain is acknowledged.

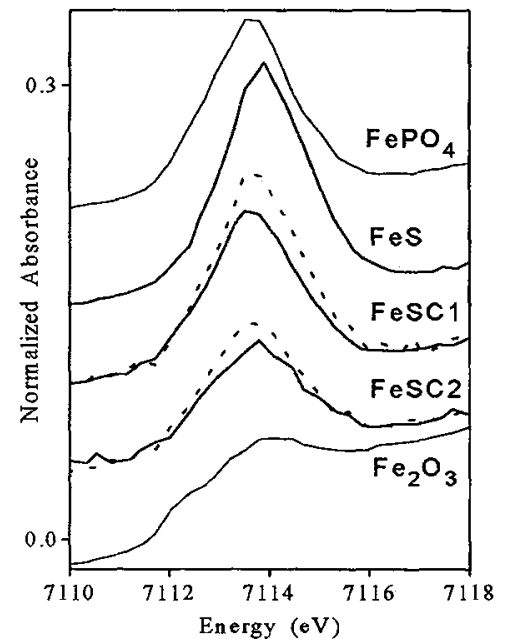

Figure 1: XANES pre edge peaks: dashed curves are referred to samples in interaction with 60 Torr of $\mathrm{NH}_{3}$

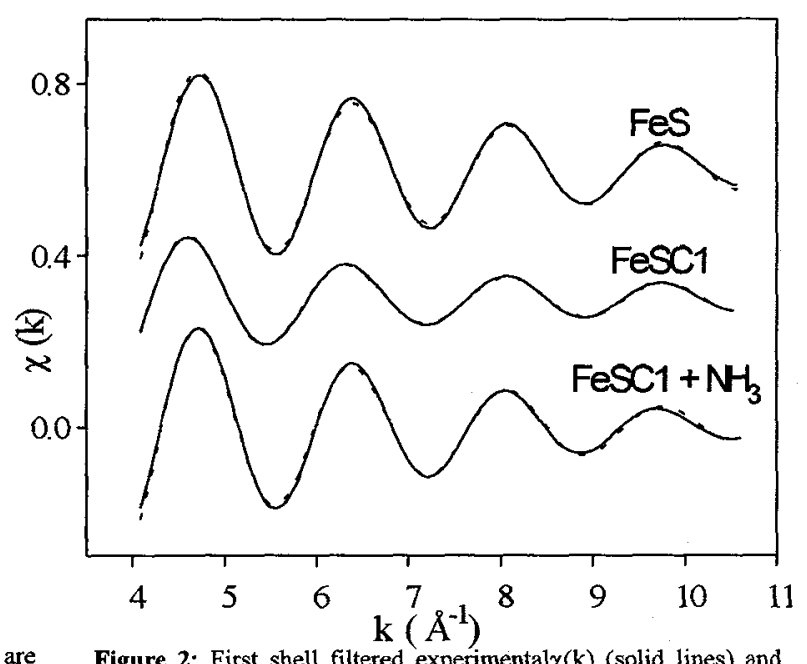

Figure 2: First shell filtered experimental $\chi(k)$ (solid lines) and corresponding fits (dashed lines)

\section{References}

[1] Szostak R. and Thomas T. L., J. Catal. 100 (1986) 555-557; Borade R. B., Zeolites 7 (1987) 398-403.

[2] Szostak R., Nair, V. and Thomas T. L., J. Chem. Soc. Faraday Trans. 183 (1987) 487-494.

[3] Bordiga S. et al., Nucl. Instr. Meth. B 97 (1995) 23-27.

[4] Bordiga S. et al., J. Catal. 158 (1996) 486-501.

[5] Zecchina A., Geobaldo F., Lamberti C., Bordiga S., Turnes Palomino G. and Otero Areán C., Catal. Lett. in press.

[6] Lytle F. W., Sayersand D. E. and Stern E. A., Co-Chairmen, Physica B 158 (1989) 701-722.

[7] Michalovicz A., Ph.D. thesis, Université Paris Val de Marne 1990.

[8] Bordiga S. et al., J. Phys. Chem. 98 (1994) 4125-4132; Catal. Lett. 26 (1994) 195-208.

[9] Calas G. and Petiau J., Solid State Commun. 48 (1983) 625-629.

[10] Patrin J., Tuilier M. H., Durr J. and Kessler H., Zeolite 12 (1992) 70-75.

[11] Scarano D. et al., J. Chem. Soc. Faradoy Trans. 89 (1993) 4123-4130.

[12] Lewis D.W. et al., Nucl. Instr. Meth. B 97 (1995) 44-49; J. Phys. Chem. 99 (1995) 2377-3283. 